LA-UR- 93-1201
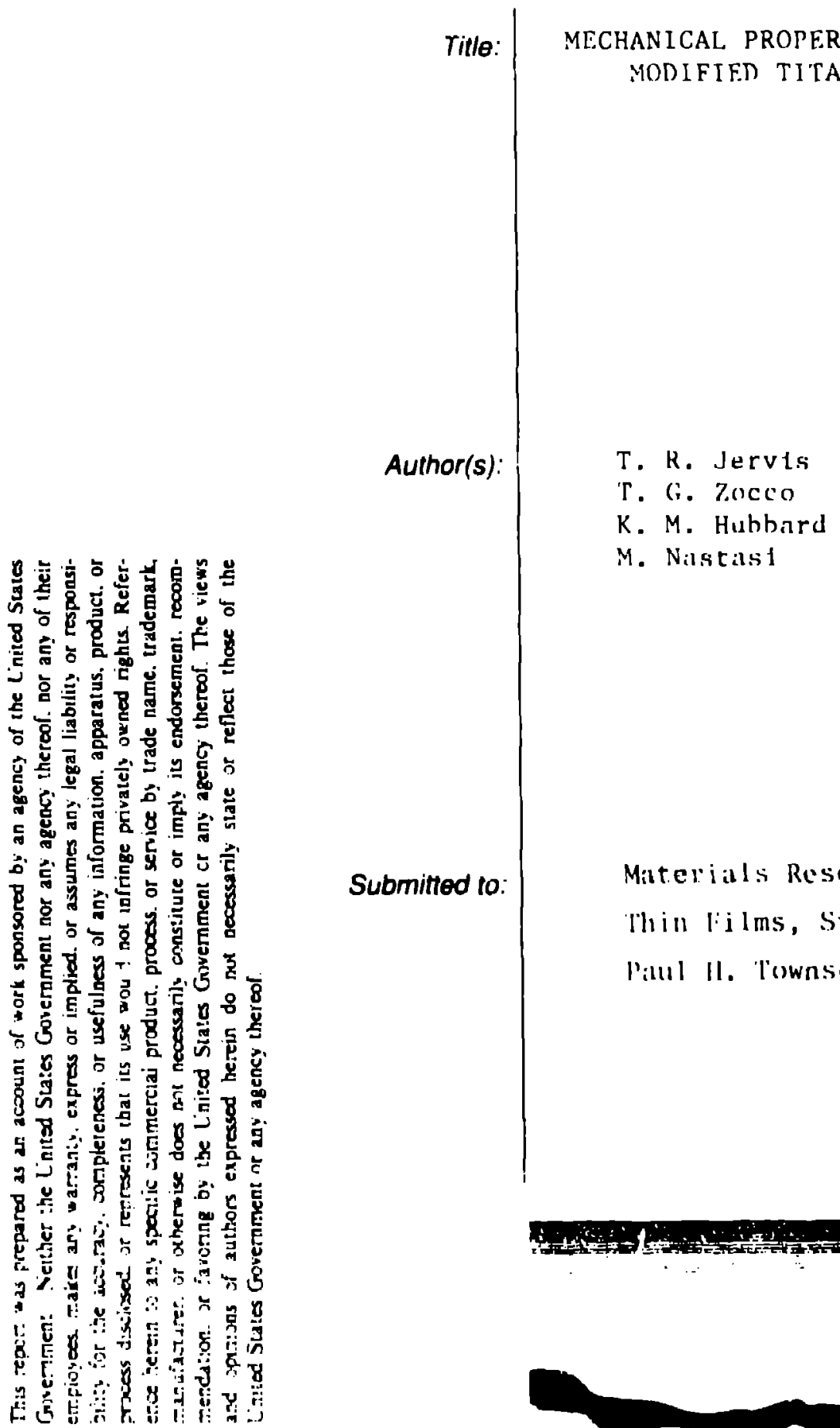

Submitted to:

Materials Rescarch Society Symposium Procechings un Thin lims, Stresses and Mechanisal lropertics dV P'alul Il. 'lownsend, liditor'
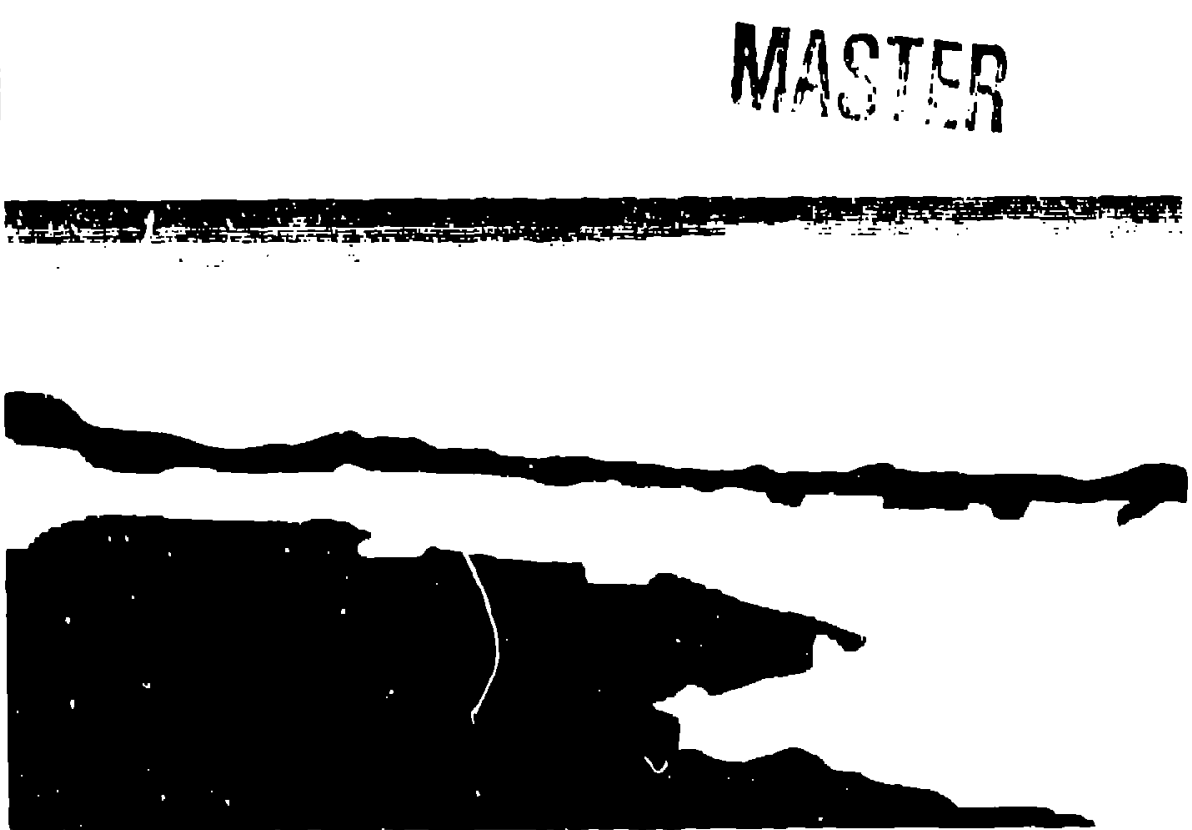

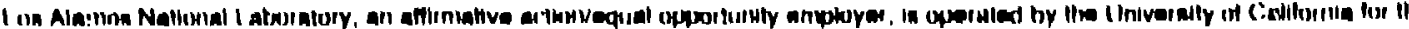

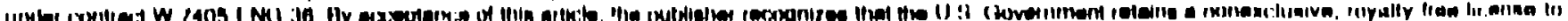

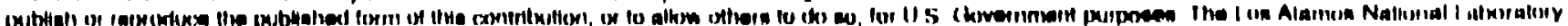

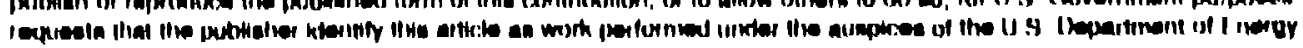




\title{
MECHANICAL PROPERTIES OF EXCIMER LASER MODIFIED TITANIUM SURFACES
}

\author{
T. R. dERVIS*, 'T. G. ZOCCO**, K. M. HUBBARD***, AND M. NASTASI*** \\ Center for Materials Science \\ Nuclear Materiais 'Technology Divison \\ Materials Science and Technology Division \\ Lus Alamos National Lathoratory, Los Alamos, NM
}

\section{ABSTRACT}

Excimer laser processing enables both thermally-driven transformations and the incorporation of solutes into the surface of materials through melting and diffusional mixing. We have examined the effect of excimer laser processing on the microstructure and surface mechanicai properties of titanium alloys. Changes in the surface hardness due to laser processing were studied using a Nanoindenter ${ }^{\mathrm{TM}}$. Alloyirig experiments using both mixing of evaporated surface layers of boron and laser gas alloying in air and in nitrogen all result in changes in the surface hardness of the material. Alloying with boron results in an amorphous surface which is somewhat harder than the as polished surface. Laser processing in air and pure nitrogen results in incorporation of oxygen and nitrogen and the development of fine $(\sim 50 \mathrm{~nm})$ precipitates of 'TiO and TiN respectively. Substantial increases in surface hardness result due to solution and precipitation mechanis: $\therefore$. The effects of alloying on the surface hardness of the materials will be discussed in terms of the concentration of the solute and microstructures observed.

\section{IN'TRODUC'TION}

The use of depth sensing indentation load measurements for materials property determinations with appropriate calibrations of indenter tip shape can provide usefil information on hardness vs depth for surface modified materials| 1, 2]. We have used nanoindenter ${ }^{\mathrm{M}}$ techniques extensively in the evaluation of surface modified materials and lind that the results of these measurements can be correlated well with depth sensitive determinations of microstructure and composition. 'This puper will present data on hardness determinations of excimer laser surface modified Ti alloys. Specifically, we will examine thermal transformations, the formation of amorphous B-T'i alloys, and solution and precipitation hardening of "T'i-fiAl-iq by laser gas alloying.

Excimer laser surfice processung has been described at length in these procoedings| 3, 4, 51. Briafly for 'li alloys, laser light at $248 \mathrm{~mm}$ wavelongth is used to molt the surface at fluences of approsimately $1.0 \mathrm{~J}-\mathrm{cm}^{2}$. Mixing with a prevously evaporated surfiser layer of some other material or with the gas ambient results in alloying with the depth of processing on the orree of a few

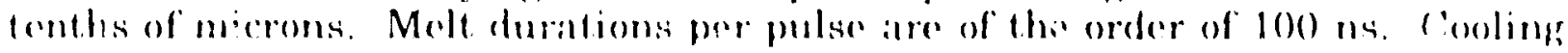
and solidifieation are very rapid, with cooling rates of the order of $1010 \mathrm{~K}$ K :

Indentation measurements were made using the commereially avaliable

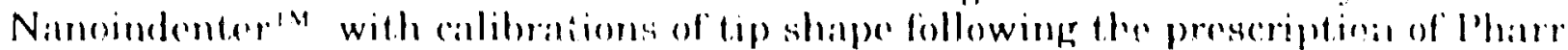

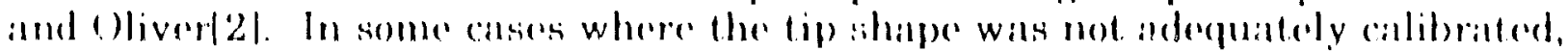

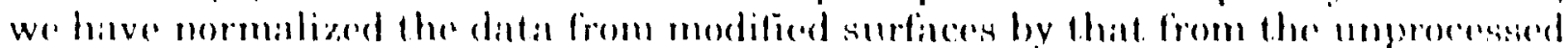

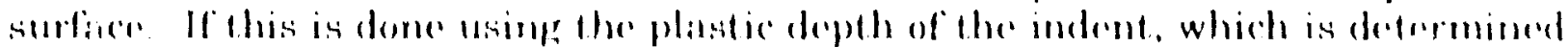
by sthblatetimg, the elastic portion of the displacement from the surface, the tip shapos calibration, or lack thereol, is removed from the result and only diflerenters

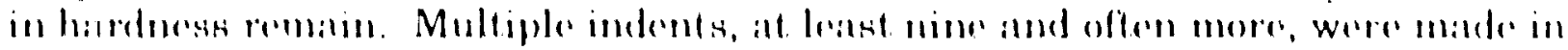


each sample and the data from multiple indents averaged to obtain the final result. Error bars shown in the data are the standard deviations of these averages, thereby representing only data scatter and not systomatic errors.

\section{RESULTS}

Surface preparation can have a significant effect on surface hardness measurements. Figure 1 shows the relative hardness as a function of depth for mechanically polished and as rolled surfaces normalized to the hardness of an electropolished surface. Clearly, mechanical polishing, in this case to a mirror finish, results in measureable work hardening to a depth greater than that of surface processing techniques.

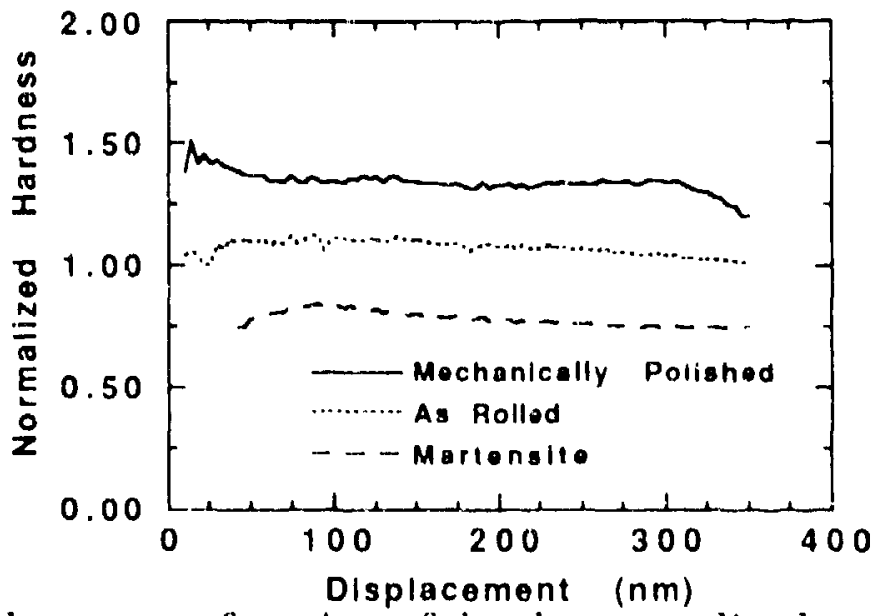

Figure 1. Hardness as a function of depth, normalized to the hardness of the electropolished surface, of mechanically polished, as rolled, and single pulse laser treated Ti-6Al-4V.

The thermal transformation of a-'T'i to a' from heating above the transformation temperature (925) (C) for Ti-6Al-4V) and cooling at rates greater than 30$) \mathrm{K}_{-} \mathrm{s}^{-1}$ is well documented|6|. Figure 1 also shows the hardness measured for a surface treated with a single pulse of excimer laser energy at $1.0 \mathrm{~J}^{-\mathrm{cm}^{-2}}$. In this case the surface is actually melted, but the transformation occurs regardless. The surface hardness is about $80 \%$ that of the electropolished surface. Thus any processing designed to harden the surface starts from this slight deficit. 'This transformation also softens the mrehanically polished surface by a comparable amount, howrver laser processing does not completely relieve the work hardening of the surface.

Boron implantation of 'l'i alloys has been suggested as a means to improve the tribological properties of these alloys. Wo have alloyed B into li-fiAl-dV by excimer laser mixing of a $(6) \mathrm{mm} 63$ surface layer into 'Ti alloy substrates/7| 11 sing 5 pulses of radiation at $2.5 .5-\mathrm{cm}^{2}$. Despite the large negative heat of formation of Til3, rapid solidification apparenty suppresses the formation of this compound and the resulting alloy is amorphous. Figure 2 shows the hardmess-depth relationship for the amorphous B'T'i alloy. Measurement af the B concentration

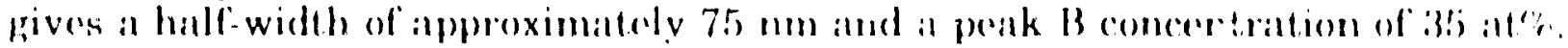

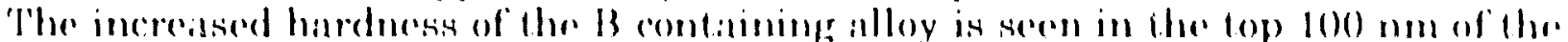
material, comsistent with the B distribution. Note that as greater depths, the hardoess is less than that of the mechancally polished startims material, consistent with the thermal transformat ion discussed alouve. 


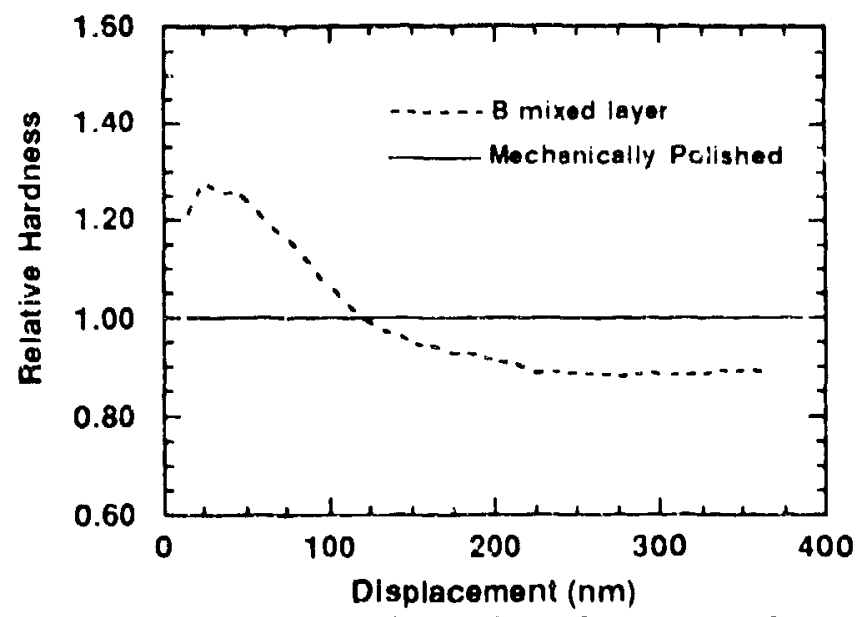

Figure 2. Hardness as a function of depth, relative to that of a mechanically polished surface, of a laser produced amorphous B-Ti alloy. The depth of the hard surface is commensurate with that of the measured $B$ concentration.

Because of the high affinity of 'Ti for oxygen and nitrogen, excimer laser alloying of the surface from gas sources is feasible. Because of the reduced density of the sarce, compared with the mixing, of solid surface layers, many more laser pulses are required to obtain significant alloying concentrations.

Laser treatment of ' $\mathrm{Ti}$ in air produces oxygen incorporation|8, 91. Oxygen is dissolved in the lattice until the equilibrium solid solubility of oxygen in ' $\mathrm{Ti}$ is exceeded, at which point $\gamma$-TiO precipitates from the solid solution. Analysis of the oxygen concentration as a function of depth for samples which do not exhibit Tio precipitation can be directly correlated with hardness vs depth information. For hardening hy this dislocation-solute interaction, one expects the hardness to follow a square root dependence on the oxygen concentration. 'This is shown in figure 3 , where the relative hardness measured at a depth of $100 \mathrm{~nm}$ is plotted $v$ s the square root of the oxygen concentration as measured by resonant elastic scattering of a particles at 3.05 MeV|10). 'These samples received between 1 and 16 pulses of laser radiation in air.

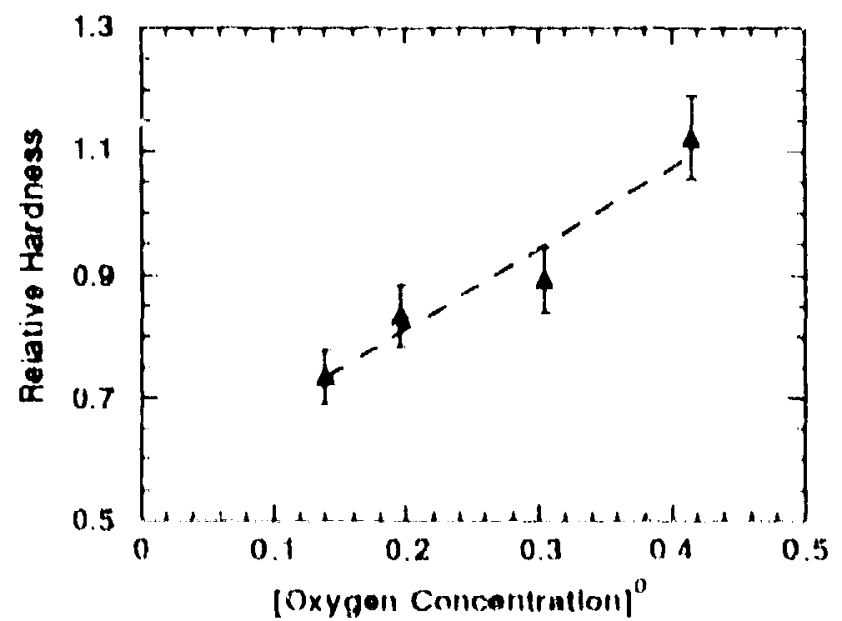

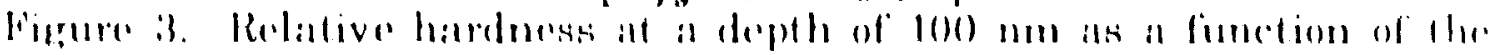

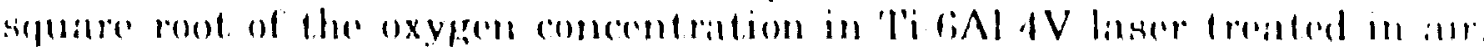

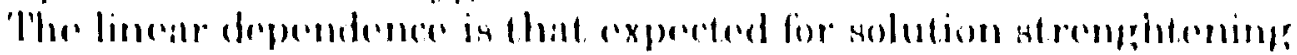


In samples treated with a sufficient number of pulses to initiate TiO precipitation, transmission electron microscopy, which gives the TiO precipitate size as a function of processing, can be joined with the oxygen concentration measurements to provide precipitate density and size as a function of depth. Observed hardness as a function of depth can then be related to the precipitate density tnrough the Orowan strengthening mechanism[11]. Figure 4 shows the dependence of the hardness on the inverse mean free path between precipitates which calculated from our data and the analysis of Corti et. al.|12|. The expected linear dependence is fcund. It should be noted thit these data include values from more than one depth in the material, correlated to the oxygen and precipitate distributions. The agreement emphasizes the validity of hardness vs depth information as obtained from the nanoindenter' ${ }^{\mathrm{m}}$. We have performed experiments with nitrogen alleying and find similar dependence of the relative hardness on the precipitation of 'liN particles.

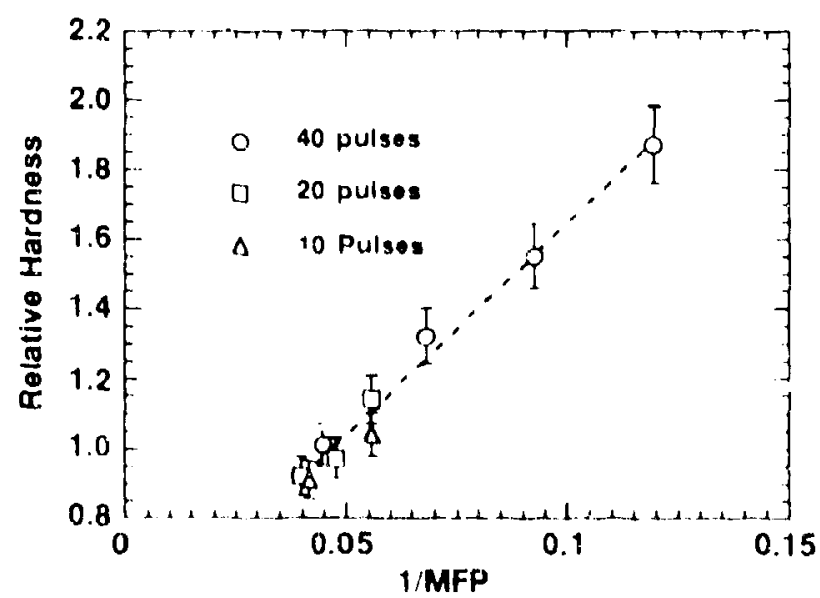

Figure 4. Relative hardness as a function of inverse mean-free-path between 'I'i() precipitates in laser processed 'Ti-6Al-4V. The data, from several depths per sample, follow the behaviour expected for dispersion strenghtening.

\section{CONCIIUSIONS}

We have demonstrated that hardness-depth information obtained from

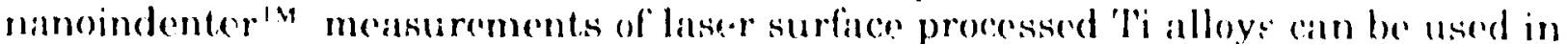
conjunction with the processing and microstructural information obtained by ofher technicgues to further illuminate the effects of these processes on the modified surfaces. The deptle sensitive information is sulficientely solf consistent to chablo comparison with theories of strengthening mochanisms and hence the determination of those mechanismis.

\section{$\Lambda($ KNOWI $: D)($ IEMENTS}

We would like to thank l)arryl (iarcia and the porsonted of the los Alames lon

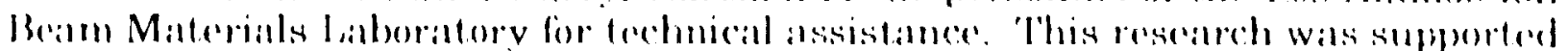

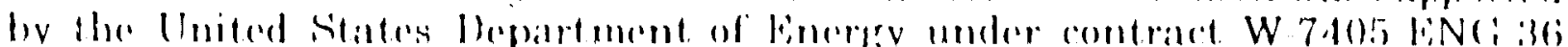

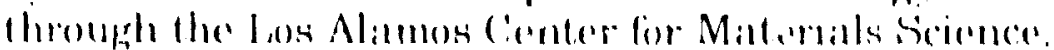




\section{REFERENCES}

1 W. C. Oliver, R. Hutchings, and J. B Pethica, ASTM Spec. Tech. Pub. 88990 (1986).

2 W. C. Oliver \& G. M. Pharr, J. Mater. Res. 71564 (1992).

3 T. R. Jervis, J-P. Hirvonen, M. Nastasi, T. G. Zocco, J. A. Martin, G. M. Pharr, \& W. C. Oliver, Nat. Res. Soc. Symp. Proc. 140189 (1989).

4 T. R. Jervis, J-P. Hirvonen, M. Nastasi, and M. R. Cohen, Mat. Res. Soc. Symp. Proc. 157395 (1990).

5 Excimer Laser Surface Modification; Process and Properties, T. R. Jervis, M. Nastasi, \& J-P. Hirvonen, In Press, Mater. Res. Soc. Symp Proc. 279 (1993).

6 D. G. Konitzer, B. C. Muddle, \& H. L. Fraser, Metall. Trans. 14A 1979 (1383).

7 'T. R. Jervis, M. Nastasi, J-P. Hirvonen, \& T. G. Zocco, Anierican Institute of Pnysics Conf. Proc. 231652 (1991).

8 T. R. Jervis, T. G. Zocco, \& J. H. Steele, Jr., Mater. Res. Soc. Symp Proc. 201 535 (1991).

9 T. R. Jervis, K. M. Hubbard, \& T. G. Zocco, Mater. Res. Soc. Symp Proc. 236 397 (1992).

10 J. R. Cameren, Phys. Rev. 908.39 ( 195.3).

$11 \mathrm{~J}$. D. Vimbury, Metall. Trans. 13 A 2191 (1985).

12 C. W. Corti, P. Cotterill, and G. A. Fitzpatrick,Int. Met. Rev. 1977 (1974). 